\title{
Sensitive Rose and the Cross-media Era
}

\author{
Martha Gabriel \\ University of São Paulo \\ Rua Ibaragui Nissui 115 ap 1204 - São Paulo - SP - Brazil \\ martha@nmd.com.br
}

\section{INTRODUCTION}

The objective of this text is to analyze the awarded artwork Sensitive Rose as a model to discuss and reflect about the potentialities of using mobile tags as tools for augmented reality and cross-media.

\section{MOBILE TAGS}

As digital technologies penetrate humans' daily lives, the possibilities for interaction and mobility have increased strongly. One of the most successful ways of leveraging mobile data input is by using 2D-barcodes (mobile tags) that can be instantly read by a mobile device with camera, like QRcodes or Datamatrix. These codes can encrypt several kinds of data, like URLs, SMS, vCard address, etc. Also, mobile tags have a huge potential to be used as cross-media transitions, allowing a quick and easy interaction creating links between different types of media. Since these tags provide a digital layer of information interacting with any physical objects, we could also say that they create an augmented reality level for those objects and this is the less expensive way of using augmented reality today. These tags are already popular and being used intensely in Japan and starting spreading around the world.

\section{SENSITIVE ROSE}

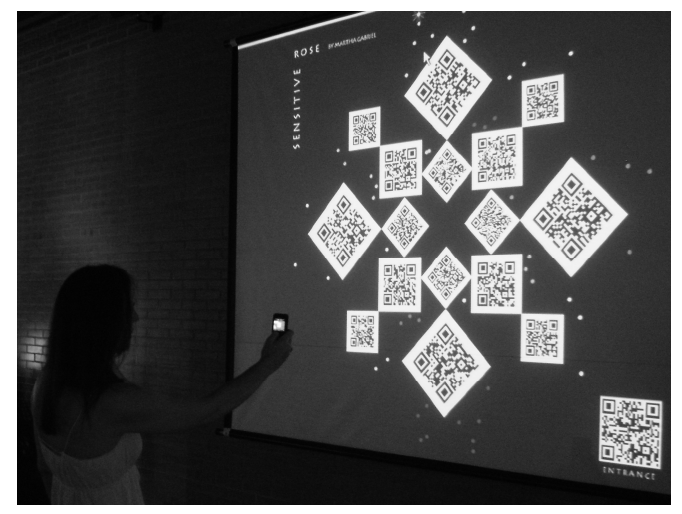

Figure 1: Photo of the artwork Sensitive Rose
In this context, it was created the artwork SENSITIVE ROSE (Gabriel, 2008), which is an interactive compass rose formed by mobile tags (QRCodes) that maps people's desires (see Fig. 1). The work is a big projection $(3 \mathrm{~m} \times 3 \mathrm{~m})$ and the interactions happen via a mobile device by scanning the entrance mobile tag on the projection.

The interactor, then, will access a mobile form to answer the question - "What do you want from life"? There are 16 options available, each one related to a tag in the work. Each interaction is shown in the work as an animation and mapped by a colored spot around the tag related to it - if the person chose love, it will cause the ball to appear next to the tag "love" and that tag gets encrypted then with the text "Joe wants love" (where Joe is the interactor's name).

The most wanted desire is always positioned North, and according to the order of relevance of the choices of the desires, all the work reconfigures itself each time the relevance changes. In this sense the work functions as a compass rose that navigate in the people's desires, showing what people want most in life. The navigation, however, must decipher the mobile tags (QRCodes) because the texts associated with each tag cannot be decoded in naked eyes but only by using a device that allow seeing beyond the surface.

Another intention of the work is to extract poetics of the QR-Codes as a visual poetry. In the same way that Concrete Poetry used alphabetic codes (letters/words) and their visual characteristics to create meaning, SENSITIVE ROSE creates a visual poetry formed by mobile tags (visual codes of information) in a way that the data input and output are done completely through the projection.

\section{REFERENCES}

GABRIEL, M. (2008) SENSITIVE ROSE. (http://www.sensitiverose.com.br). 